\title{
Correspondence
}

\section{Incidence of gastric side effects in controlled trials with unbranded aspirin and with various long-acting aspirin preparations}

\section{Sir,}

Huskisson and Scott (1978) record an amazingly high incidence of gastric side-effects with 'aspirin' in osteoarthrosis, but offer no comment on this nor on the form of aspirin used.

\begin{tabular}{|c|c|c|c|c|}
\hline \multirow[t]{2}{*}{ Reference } & \multicolumn{2}{|l|}{ 'Aspirin' } & \multicolumn{2}{|c|}{ Named aspirin preparations } \\
\hline & $\begin{array}{l}\text { Gastric side } \\
\text { effects }\end{array}$ & $\begin{array}{l}\text { Daily dose } \\
(\mathrm{g})\end{array}$ & $\begin{array}{l}\text { Gastric side } \\
\text { effects }\end{array}$ & $\begin{array}{l}\text { Daily dose } \\
(g)\end{array}$ \\
\hline \multirow{2}{*}{$\begin{array}{l}\text { Huskisson an } \\
\text { Scott (1978) } \\
\text { Sperryn et al. } \\
\text { (1973) }\end{array}$} & $\begin{array}{l}\text { nd } \\
10 / 16(63 \%)\end{array}$ & $3 \cdot 6$ & & \\
\hline & $10 / 21(48 \%)$ & 4.0 & $5 / 20(25 \%)$ & $\begin{array}{l}4 \cdot 0 \\
\text { (Benoral) }\end{array}$ \\
\hline $\begin{array}{l}\text { Hill et al } \\
\text { (1974) } \\
\text { Billings et al }\end{array}$ & $8 / 50(16 \%)$ & $4 \cdot 0$ & & \\
\hline & $3 / 20(15 \%)$ & $4 \cdot 0$ & & \\
\hline $\begin{array}{l}\text { Shepard } \\
\text { (1969) }\end{array}$ & $\begin{array}{l}48 / 513^{*} \\
(0.9 \%)\end{array}$ & Variable & $\begin{array}{l}30 / 697^{*} \\
(0.4 \%)\end{array}$ & $\begin{array}{l}\text { Variable } \\
\text { (Breoprin) }\end{array}$ \\
\hline $\begin{array}{l}\text { Dippy et al. } \\
\text { (1976) }\end{array}$ & & & $\begin{array}{l}17 / 48(35 \%) \\
15 / 48(31 \%)\end{array}$ & $\begin{array}{l}4.5 \text { (Nuseal } \\
\text { aspirin) } \\
4.5 \\
\text { (Laevius) }\end{array}$ \\
\hline
\end{tabular}

*Patient weeks in a long-term trial.

Few rheumatologists would expect such a high level of gastric side-effects, and most use quality aspirin of known brand rather than 'aspirin' (any old ... and unspecified). A review of a few controlled studies, in which 'aspirin' (any old ... and unspecified) was used, shows a variable incidence of gastric side-effects but none as high as those recorded by Huskisson and Scott.

J. M. GUMPEL Northwick Park Hospital and Clinical Research Centre, Harrow, Middlesex HA1 3 UJ.

\section{References}

Billings, R., Burry, H. C., Grahame, R., and Berry, D. J. (1975). A double blind crossover trial of prenazone and aspirin in the management of rheumatoid arthritis. Rheumatology and Rehabilitation, 14, 61-66.

Dippy, J., Pritchard, M. H., and Lloyd, K. N. (1976). Aspirin in rheumatoid arthritis: a comparison of micro- encapsulated and enteric coated. Rheumatology and Rehabilitation, 15, 77-80.

Fosdick, W. M., and Shepard, W. L. (1969). Enteric-coated microspherules. A clinical appraisal of two forms of aspirin. Journal of Clinical Pharmacology, 9, 126-129.

Hill, H. F. H., Hill, A. G. S., Mowat, A. G., Ansell, B. M., Mathews, J. A., Seifert, M. H., Gumpel, J. M., and Christie, G. A. (1974). Naproxen, A new non-hormonal antiinflammatory agents. Annals of the Rheumatic Diseases, 33, 12-000.

Huskisson, E. C., and Scott, J. (1978). Sulindac. Trials of a new anti-inflammatory drug. Annals of the Rheumatic Diseases, 37, 89-92.

Sperryn, P. N., Hamilton, E. B. D., and Parsons, V. (1973). Double blind comparison of aspirin and benorylate in rheumatoid arthritis. Annals of the Rheumatic Disease, 32, 157-161.

\section{Thoracolumbar spine abnormalities in rheumatoid arthritis}

\section{Sir,}

Sims-Williams et al. (1977) recently described 6 patients with rheumatoid arthritis and lumbar spinal abnormalities. All patients demonstrated osseous erosion about

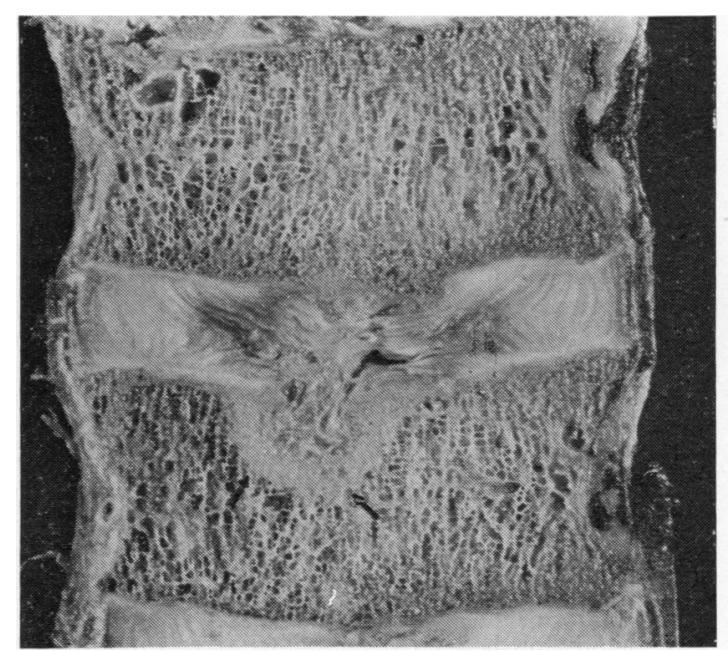

Fig. 1 Intervertebral disc degeneration (intervertebral osteochondrosis). Note herniation of a portion of the nucleus pulposus into the vertebral body with surrounding bone sclerosis (arrows). 


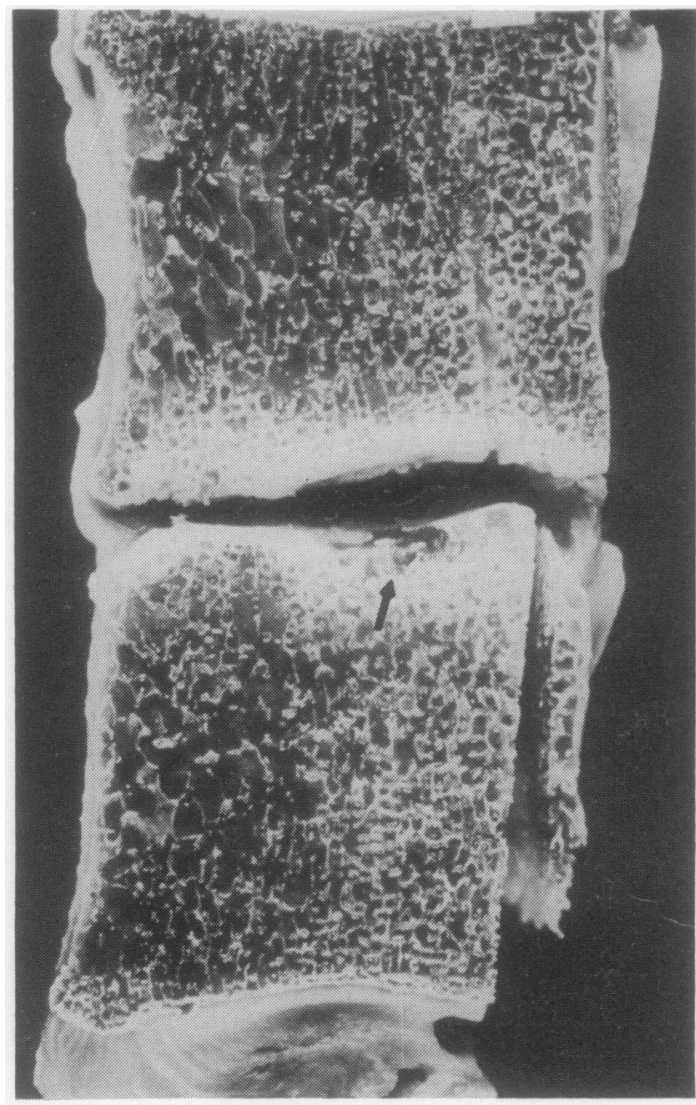

(a)

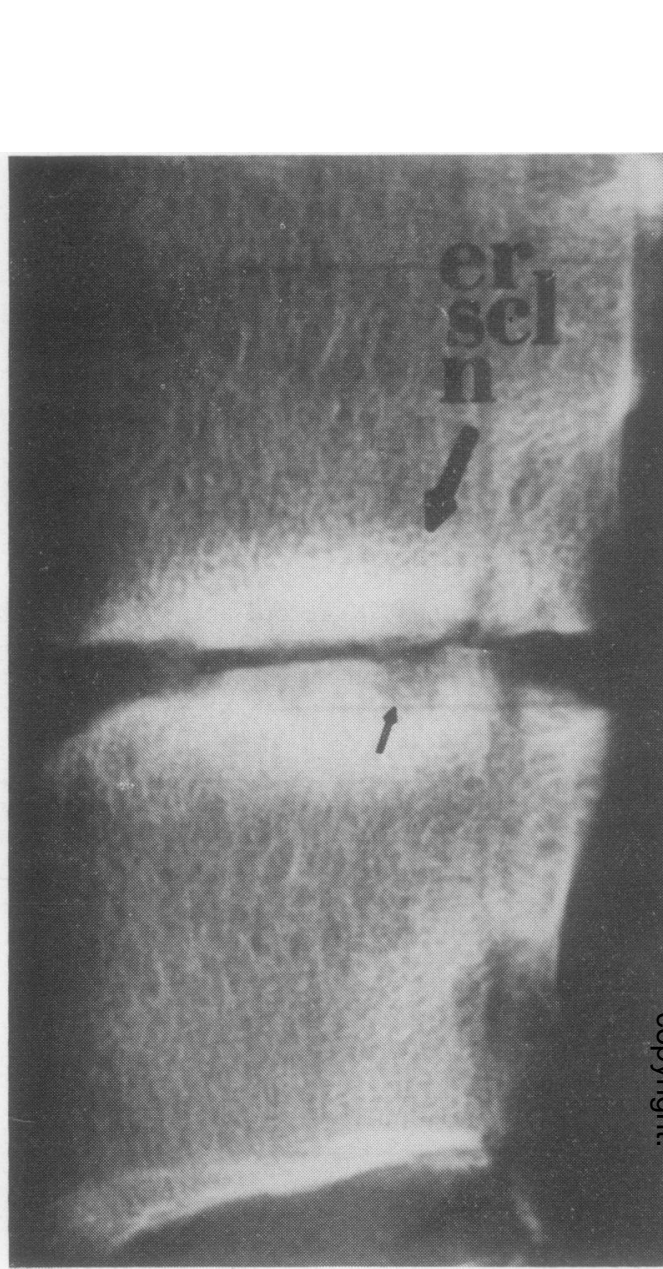

(b)

Fig. 2 Rheumatoid arthritis. (a) Pathological and (b) radiological observations include intervertebral disc narrowing (n), bone erosion (er), and sclerosis (scl). Note cartilaginous node formation (arrows).

apophyseal joints and 2 had alterations at the discovertebral junction. The authors speculated that these discovertebral changes might be related to apophyseal joint involvement in one of two ways: (1) apophyseal joint instability might lead to abnormal motion at the discovertebral junction or (2) inflammatory synovial tissue might extend from the apophyseal joints directly into the discs. These investigators also noted 2 other possible mechanisms for discovertebral changes in rheumatoid arthritis: synovial infiltration into fissures within the degenerating nucleus pulposus of the intervertebral disc or neuropathic alterations secondary to analgesic or steroid therapy.

It has previously been attractive to suggest that inflammatory tissue in rheumatoid arthritis might extend from a synovial joint to an adjacent intervertebral disc. In this manner, one could account for cervical disc lesions related to inflammation in the neighbouring 'synoviallined' joints of Luschka, and thoracic and lumbar disc lesions related to synovial inflammation in the apophysead. or, in the case of the thoracic spine, costovertebral joint

Recently, Martel (1977) has suggested that cervica discovertebral destruction in rheumatoid arthritis is at consequence of cervical instability caused by apophysea arthritis and ligament laxity. Supporting evidence for this concept are the appearance of apophyseal join destruction at the same level as the involved discoi vertebral junction, the close apposition of vertebra bodies in the area of vetebral change, the absence of inflammatory change on microscopic evaluation of the disc, and the absence of similar lesions in juvenile-onset rheumatoid arthritis in which bony ankylosis of the apophyseal joints may protect the adjacent discos vertebral junction.

Our radiological and pathological observations if patients with rheumatoid arthritis (and related disordersy support the concept that vertebral lesions in this articula disease may relate to occult trauma at the discovertebr制 
junction (Resnick and Niwayama, 1978). Such trauma may predispose to intravertebral herniation of portions of the disc producing cartilaginous or Schmorl's nodes. In rheumatoid arthritis, apophyseal joint instability and vertebral body osteoporosis may contribute to the incidence of such cartilaginous node formation. The similarity of radiographically evident rheumatoid discovertebral alterations (such as disc space loss, subchondral radiolucent vertebral lesions, and reactive bone sclerosis), to changes accompanying other disorders characterised by cartilaginous node formation is noteworthy. These latter disorders include any process which weakens either the cartilaginous end-plate of the vertebral body or the subchondral bone such as trauma, degenerative disease of the nucleus pulposus (intervertebral osteochondrosis) (Fig. 1), metabolic and endocrine disorders (Resnick and Niwayama, 1976). Furthermore, direct inspection of thoracic and lumbar spine specimens in some rheumatoid cadavers has documented the presence of cartilaginous nodes within sclerotic vertebral bodies, about narrowed intervertebral discs (Fig. 2). The resulting radiological picture in these cadavers simulates infection, although the vertebral outline is generally better defined than in patients with infective spondylitis.
In any case, the observation that thoracolumbar spine changes occur in rheumatic arthritis is certainly important and should stimulate further investigation in order to outline the pathogenesis of these lesions, investigation that requires close radiological-pathological correlation

DONALD RESNICK Department of Radiology, Veterans Administration Hospital, 3350 La Jolla Village Drive, San Diego, California 92161, USA

\section{References}

Martel, W. (1977). Pathogenesis of cervical discovertebral destruction in rheumatoid arthritis. Arthritis and Rheumatism, 20, 1217-1225.

Resnick, D., and Niwayama, G. (1976). Subchondral resorption of bone in renal osteodystrophy. Radiology, 118, 315-321.

Resnick, D., and Niwayama, G. (1978). Intravertebral disc herniations: cartilaginous (Schmorl's) nodes. Radiology, 126, 57-65.

Sims-Williams, H., Jayson, M. I. V., and Baddeley, H. (1977). Rheumatoid involvement of the lumbar spine. Annals of the Rheumatic Diseases, 36, 524-531.

\section{Serum copper levels in rheumatoid arthritis}

Sir,

Recent correspondence concerning the level and distribution of copper in the serum of patients undergoing therapy for rheumatoid arthritis (Bajpayee, 1975; Sorensen, 1976a) and observations that copper complexes of anti-inflammatory drugs are more active in animal models than the drugs themselves (Sorensen, 1976b) suggest that copper may possibly play an important, if little understood, role in the inflammatory process. Accordingly, the serum copper levels of a group of patients with rheumatoid arthritis who were undergoing therapy with different drug regimes were measured (Table). All subjects in the group had been treated with the drug indicated in the Table for at least 1 month before analysis of a sample of serum for copper by atomic absorption spectrometry using carbon furnace atomisation (Kamel et al., 1978). The results suggest that there is a correlation between serum copper level and drug therapy and, in particular, the levels found with aspirin and indomethacin are significantly different from non-rheumatoid controls at the $0.1 \%$ level.
We attempted to assess the effect of the duration of therapy over a period of 6 months by following the serum copper levels of selected patients who remained for that length of time on each drug listed except gold. Penicillamine produced a definite reduction in the average serum value during this period and, indeed, in some patients a level close to that of the controls was achieved. With aspirin, indomethacin, and levamisole there were some variations but no obvious trends were observed with these drugs in the time scale of this investigation. Previous studies have referred to groups of 'untreated' rheumatoids (Bajpayee, 1975; Sorensen, 1976a) but in our case all patients had been treated in some manner previously. Their copper levels before hospital treatment varied from $2 \cdot 15$ to $1 \cdot 11 \mathrm{mg} / \mathrm{ml}$.

The correlation between drug therapy and copper level was somewhat unexpected. Serum copper variations have been noted for quite a wide range of physiological conditions such as sex, pregnancy and contraception, stress and diurnal rhythms and these effects might have been expected to obscure any drug-related changes. However,

Table Serum copper levels of patients with rheumatoid arthritis undergoing therapy with different drugs

\begin{tabular}{lllllll}
\hline & Controls & Indomethacin & Aspirin & Levamisole & Penicillamine & Gold \\
\hline Number & 17 & 21 & 15 & 49 & 7 & 14 \\
Mean copper level $(\mu \mathrm{g} / \mathrm{ml})$ & 1.03 & 1.65 & 1.61 & 1.37 & 1.32 & 7.65 \\
Standard deviation & 0.15 & 0.20 & 0.18 & 0.28 & 0.18 & 0.42 \\
\hline
\end{tabular}

